\title{
If you're 120
}

\section{Tom Dening}

\author{
If you're 120 \\ You've lived for almost 44000 days \\ Through 30 leap years \\ You could have blown out 7000 birthday \\ candles \\ You'd have been in middle age by World War I \\ You could have known folk who remembered \\ Waterloo \\ You might well think de Gaulle was still in \\ charge \\ In your lifetime cars, computers, tumble dryers \\ came \\ If you're 120 \\ There wouldn't be any schoolfitends left \\ Your grandchildren could be 80 plus \\ They might die of old age first
}

You'd be rather small by now

Nor see too well, nor hear

Need help with washing. dressing, maybe feeding By vital village girls of six generations on

If you're 120

You might not bother thinking much

You wouldn't need to plan

Sit and smile secretly, instead

You couldn't buy a house, insurance, holidays

You don't run, cook, make love any more

They spoll you rotten and make a birthday fuss

Nobody's been this old before.

Tom Dening. Consultant Psychiatrist, Fulbourn Hospital, Cambridge CB1 5EF

\section{Only one patient}

\section{Larry Culliford}

There is only one patient: oneself.

Look at them before you, one at a time. Do not two eyes, nose, mouth, ears mirror your own? This patient - this person - is endowed like you with vision, hearing, taste, smell, touch. Also feelings: sorrow and joy; anxiety, peacefulness; anger, guilt, shame, bewilderment, equanimity. Is this not so?

"But thoughts, words, deeds: these are different", you say.

Do not words and deeds begin with and depend upon our thoughts?

When did you last, in meditation, watch your thoughts pass by uncensored? And have you recently studied your dreams dispassionately, without fear? Is there no imagination within you? Are there any impulses to speech or action you could perhaps have forgotten?

Heart and mind: these do not so easily forget. Everyone's blood is red. Everyone's tears are salty. If you know even a little something about empathy, you will know what I mean. And you will have the gratitude of many.

Larry Culliford, Consultant Psychiatrist, Brighton Community Mental Health Centre, 79, Bucketngham Road, Brighton BNI 3RJ 